\title{
A fuzzy MCDM model with objective and subjective weights for evaluating service quality in hotel industries
}

\author{
Nima Zoraghi ${ }^{*}$, Maghsoud Amiri $^{2}$, Golnaz Talebi ${ }^{3}$ and Mahdi Zowghi ${ }^{4}$
}

\begin{abstract}
This paper presents a fuzzy multi-criteria decision-making (FMCDM) model by integrating both subjective and objective weights for ranking and evaluating the service quality in hotels. The objective method selects weights of criteria through mathematical calculation, while the subjective method uses judgments of decision makers. In this paper, we use a combination of weights obtained by both approaches in evaluating service quality in hotel industries. A real case study that considered ranking five hotels is illustrated. Examples are shown to indicate capabilities of the proposed method.
\end{abstract}

Keywords: Service quality; Hotel ranking; FMCDM; Objective weight; Subjective weight

\section{Introduction}

The tourism sector plays a vital role in the country's economy, and it generates income through the consumption of goods and services by tourists. Travelers usually seek a functional and comfortable hotel. In this sense, modern economic development is characterized by an increasing emphasis on market demand, and as a part of this process, the tourism industry also places a strong focus on understanding tourist needs and wants. However, hotels are facing to increasing competition from other lodging units including bed-and-breakfasts and campgrounds. This increased competition has forced traditional tourist hotels to find ways to retain current clients and to attract competitors' clients. Increased service quality through increased employee performance is a viable way for hotels to remain competitive.

Under these circumstances, hotel corporations not only attempt to establish more adequate services, but also introduce more promotional incentives to attract consumers. Hotels would like to increase their market shares and enhance profitability. However, the marginal benefits of marketing strategies are beginning to shrink because most of the actors have similar plans. Having in mind

\footnotetext{
* Correspondence: Nima.Zoraghi@gmail.com

${ }^{1}$ Faculty of Industrial and Mechanical Engineering, Islamic Azad University, P.O. Box 34185-1416, Qazvin Branch, Qazvin, Iran

Full list of author information is available at the end of the article
}

this limitation, some of the hotels now tend to focus on the commitment of improving customer services. The evaluation of service quality in the hotel industry is an ongoing process that appeals a continuous monitoring to maintain high levels of service quality across a number of different service criteria (Benítez et al. 2007). To address this important issue, in this study, we investigate using fuzzy multi-criteria decision making to rank and evaluate hotel service quality.

The rest of the paper is organized as follows: In the 'Literature' section, we review past research about service quality evaluation and multi-criteria decision-making approach in hotel industries. The proposed method and its steps are described at detail in the 'The proposed FMCDM method' section. In the 'Numerical illustration' section, a real case study to appraise the service quality in some Iranian hotels is presented. Finally, conclusions and final remarks are in the 'Conclusions' section.

\section{Literature review}

The tourist hotel industry has become one of the most competitive among the service industries worldwide. To stand out in the hotel industry, excellent service quality plays the most important role for competitiveness. Service quality not only has a positive and direct effect on competitiveness, but also has an indirect positive effect via other variables such as occupancy level and average direct 
costs (Harrington and Akehurst 2000). Service quality has become critical to the profitability of the tourism sector and to the growth of tourism worldwide (Briggs et al. 2007).

In this sense, service quality in the hotel industry has been discussed in a number of studies, and there are a number of models that conceptualize the construct of service quality (e.g., Gronroos 2001; Bienstock et al. 1997). Dube and Renaghan (1999) remarked that most hotels accommodate tourists from different market segments and each group assigns different importance to distinct service areas. Phillips and Sipahioglu (2004) demonstrated that a hotel can achieve competitive advantages if its inputs, processes, outputs, markets, and environmental characteristics are congruent with the business objectives. The overall performance of a hotel comprises many dimensions, such as its management, occupancy, and catering abilities. The evaluation of each dimension could lead to different managerial actions Sun and Lu (2005). Callan (1999) focused on identifying the relation between the consumers' criteria when they select a hotel. Parasuraman et al. (1985) defined the dimensions of service quality by reliability, responsiveness, competence, access, courtesy, communication, credibility, security, understanding, and knowing the customers and tangibles.

The literature uses various approaches for assessing service quality, such as SERVQUAL (see Asubonteng et al. (1996) for more details). The SERVQUAL method assumes that the customers' (guests') perception of service quality is the only relevant factor when measuring service quality. This method is based on a questionnaire and considers guests' expectations and perceptions. However, SERVQUAL cannot apply for ranking services because it is a reflection of the consumer's long-term mentality on service qualities. Ting (2003) has also applied five dimensions of service quality to show that gaps exist between employees and customer expectations of service quality. Rozman et al. (2009) in their research are to address the tourist farm service quality evaluation problem with an application of the qualitative multiple criteria decision-making (MCDM) modeling methodology DEX. However, they demonstrated that SERVQUAL does not include two important criteria: service implementation and the relationship between service quality and price. The DEX method has already been successfully used for the estimation of hotel service quality and has been applied in the case of tourist farms. In addition, there are limitations related to interviewing respondents before and after the consumption of a given service (Akama and Kieti 2003). Additional evidence is provided by Augustyn and Seakhoa-King (2004) who concluded that the SERVQUAL scale is an insufficient measure of quality in the tourism sector. Benítez et al. (2007) demonstrated two significant contributions to tourism: marketing and hospitality. They denoted that tourists' appraisal of service quality in these hotels comprises 13 different dimensions. To do this, the fuzzy numbers as a merit methodology to dominate the ambiguity of subjective judgment concepts are employed.

To evaluate quality of services in the hotel industry, we first need to identify a number of idiosyncratic service criteria that are under the control of hotel managers. The quality of services perceived by its customers can then be represented and measured by these criteria. In this sense, quite a few models have been formulated to evaluate quality of service as a weighted sum of beliefs about the service criteria. For this purpose, MCDM techniques support decision makers (DMs) in evaluating a set of alternatives based on multi-criteria value (Keeney and Raiffa 1993).

The decision problem of selecting an information system can be described as a complex, multi-objective task, based on uncertain data. The decision process of selecting an appropriate alternative usually has to take many factors into consideration, for instance, organizational needs and goals, risks, benefits, and limited resources. In addition, because of the vagueness of human being's thought, the selection is often based on inadequate information or personal judgments. Decision makers may find it hard to identify the best choice due to the lack of systematic methods to deal with multi-criteria problems since some critical factors are basically determined by subjective perceptions. MCDM is the approach that deals with the ranking and selection of one or more vendors from a pool of providers (Shyur and Shih 2006). MCDM has been one of the fastest growing areas of operational research as it is often realized that many concrete problems can be represented by several (conflicting) criteria (Yeh et al. 1999).

Since the early 1970s, MCDM techniques have been developed into many forms and have been employed for a wide range of different case studies. Well-known MCDM methods include the total sum method, simple additive weighting method, analytical hierarchy process, analytic network process, data development analysis, case-based reasoning, outranking approaches ELECTRE (especially ELECTRE II and ELECTRE III), PROMETHEE, fuzzy set theory, genetic algorithm, mathematical programming, simple multiattribute rating technique, TOPSIS method, and their hybrids (Hwang and Yoon 1981).

The MCDM problems may be divided into two kinds (Wang and Lee 2007). One is the classical MCDM problems (Feng and Wang 2000), among which the ratings and the weights of criteria are measured in crisp numbers. The other MCDM category is the fuzzy multi-criteria decision-making (FMCDM) problems (Hsu and Chen 1996; Wang et al. 2003), among which the ratings and the 
weights of criteria evaluated on imprecision, uncertainty, and vagueness are usually expressed by linguistic terms and then set into fuzzy numbers (Zadeh 1965; Zimmermann 1991). Bellman and Zadeh (1970) first introduced the fuzzy set theory into MCDM as an approach to effectively deal with the inherent imprecision, vagueness, and ambiguity of the human decision-making process. Since then, many researchers have been working on the process with uncertain data. Under many circumstances where performance rating and weights cannot be given precisely, the fuzzy set theory is introduced to model the uncertainty of human judgments.

There are several approaches to determine the weights of criteria, and we can divide those approaches into subjective and objective approaches. The subjective approach determines weights purely according to the consideration or judgments of decision makers, while the objective approach selects weights through mathematical calculations, which neglect the subjective judgment information of decision makers. Since either subjective or objective approach has its advantages and disadvantages, an integrated or combined method seems more desirable in the determination of criteria weights (Liu and Kong 2005). To cope with this issue, we used fuzzy logic to investigate a method based on subjective and objective weights in formulating MCDM for ranking hotels. This paper proposes an integrated approach to determine weights for solving MADM problems, where the decision matrixes for each criterion is given by DM from questionnaires. It is to determine weights by solving a mathematical programming model and to reflect both the subjective considerations of the DM as well as the objective information.

\section{The proposed FMCDM method}

The MCDM problems are organized as a matrix in which some alternatives evaluate the conflicts of some criteria. For each criterion, we must assign a weight that describes its relativity importance. The best alternative is obtained by the affected weight vector on the decision matrix. Note that, when applying the fuzzy numbers in MCDM problems, it transforms to fuzzy MCDM which is called FMCDM.

In typical MCDM approaches, weights of attributes reflect the relative importance of the decision-making process. Because the evaluation of criteria entails diverse opinions and meanings, we cannot assume that each evaluation criterion is of equal importance (Chen et al. 2003). Several approaches have been proposed to determine weights (Hwang and Yoon 1981). Majority of them can be classified into subjective and objective approaches depending on the information provided. There are two weighting categories: subjective and objective methods (Ma et al. 1999). The subjective methods determine weights solely according to the preference or judgments of decision makers, and then some mathematic methods such as the eigenvector method, weighted least square method, Delphi method, and mathematical programming models are applied to calculate the overall evaluation of each decision maker. The objective methods determine weights by solving mathematical models automatically without any consideration of the decision maker's preferences, for example, the entropy method and multiple objective programming.

To ensure that the evaluation result will be affected by the weighting approaches, subjective weighting and objective weighting methods are both utilized in the comparison. The use of subjective weighting is based on the decision maker's expertise and judgment; nevertheless, objective weighting is based on mathematical computation. The approach with objective weighting is particularly applicable for situations where reliable subjective weights cannot be obtained (Deng et al. 2000). In another point of view, weights determined by subjective approaches reflect the subjective judgment or intuition of the DM, but analytical results or rankings of alternatives based on the weights can be influenced by the DM due to his/her lack of knowledge or experience. Objective approaches often determine weights by making use of mathematical models, but they neglect the subjective judgment information of the DM. This integration overcomes the shortage which occurs in either a subjective approach or an objective approach. The advantage of the proposed approach is that it not only benefits from the decision maker's expertise but also involves end users in the whole decision-making process.

Classical fuzzy MCDM problems usually assume that there are $m$ feasible alternatives $A_{i} ; i=1, \ldots, m$, with each of the alternatives having $n$ criteria $C_{j} ; j=1, \ldots, n$, and the weight of each criteria being $w_{j} ; j=1, \ldots, n$. The goal of decision making is to find the most satisfactory among the $m$ alternatives. Generally in FMCDM, weights of each criterion and the members of the decision matrix are made as linguistic terms by decision makers. These linguistic terms can be expressed in positive triangular fuzzy numbers obtained using the questionnaires. The steps of our proposed fuzzy MCDM approach can be expressed as follows:

1. Step 1. Create a decision matrix: assume that there are $m$ alternatives $A_{i} ; i=1, \ldots, m$ to be assessed against $n$ criteria $C_{j} ; j=1, \ldots, n$. We also assume that $t$ is the number of decision makers; therefore, our decisionmaker vector is demonstrated by $D_{k} ; k=1, \ldots, t$. Subjective assessments are to be made by DM to distinguish the weighting vector and the decision matrix $\tilde{Y}_{i j} ; i=1, \ldots, m ; j=1, \ldots, n$, using the linguistic terms (each $\tilde{Y}_{i j}$ is demonstrated by $\left.\tilde{Y}_{i j}=\left(y_{i j}^{l}, y_{i j}^{m}, y_{i j}^{r}\right)\right)$. 


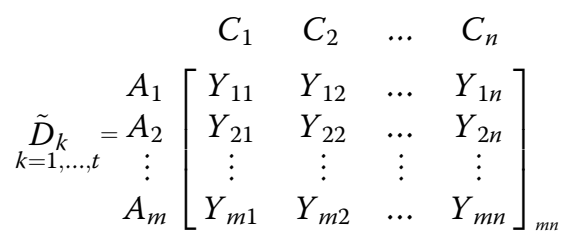

Assume that all values for each criterion are scaled between 0 and 1 to have the same range of measurement, thereby, the decision matrix needs to be normalized for each criterion $C_{j} ; j=1, \ldots, n$.

Step 2. Some of the criteria have positive concepts, thus DMs want to increase them (e.g., benefit), versus some of criteria have negative concept where DMs want to decrease them (e.g., cost). Normalization of any columns is performed separately. If $j$ th criterion of the decision matrix has a positive concept, then $\tilde{Y}_{i j}$ is normalized by dividing each elements of $\tilde{Y}_{i j}$ by the maximum of their right-hand numbers (Awasthi et al. 2010):

$$
\begin{aligned}
\underset{k=1, \ldots, t}{\tilde{D}_{k}^{N^{+}}=} & {\left[\tilde{Y}_{i j}=\left(\frac{y_{i j}^{l}}{\operatorname{Max}_{i \in(1, \ldots, m)} y_{i j}^{r}} ; \frac{y_{i j}^{m}}{\operatorname{Max}_{i \in(1, \ldots, m)} y_{i j}^{r}} ; \frac{y_{i j}^{r}}{\operatorname{Max}_{i \in(1, \ldots, m)} y_{i j}^{r}}\right)\right]_{m n} ; } \\
& i=1, \ldots, m ; j=1, \ldots, n
\end{aligned}
$$

whereas if the $j$ th criterion of the decision matrix has a negative concept, then $\tilde{Y}_{i j}$ is normalized by dividing of each elements of $\tilde{Y}_{i j}$, to maximum of their left hand numbers as follows (according to preliminaries mention in the Appendix):

$$
\begin{aligned}
& \underset{\tilde{D}_{k}}{N_{k=1, \ldots, t}^{N^{-}}}=\left[\tilde{Y}_{i j}=\left(\frac{\underset{i \in(1, \ldots, m)}{\operatorname{Min}} y_{i j}^{l}}{y_{i j}^{r}} ; \frac{\underset{i \in(1, \ldots, m)}{\operatorname{Min}} y_{i j}^{l}}{y_{i j}^{m}} ; \frac{\underset{i \in(1, \ldots, m)}{\operatorname{Min}} y_{i j}^{l}}{y_{i j}^{l}}\right)\right]_{m n} ; \\
& i=1, \ldots, m ; \quad j=1, \ldots, n
\end{aligned}
$$

Step 3. In this step, a new weight determination approach to retain the merits of both subjective and objective weights is calculated:

Step 3.1. Subjective weights. These weights can reflect the subjective judgments of the decision makers without considering the alternatives. In order to bring real-life conformations, we apply linguistic terms for describing the importance of criteria. The weighting vector $\tilde{W}=$ $\left(\tilde{w}_{1 k}, \ldots, \tilde{w}_{n k}\right)$ represents the relative importance of the $n$ selection criteria $C_{j} ; j=1, \ldots, n$ with respect to the $k$ decision maker's $D_{k} ; k=1, \ldots, t$. Note that each weight consists of three components: $\tilde{w}_{j k}=\left(e_{j k}^{l}, e_{j k}^{m}, e_{j k}^{r}\right) ; j=1, \ldots, n$; $k=1, \ldots, t$. All MCDM approaches is started by a subjective weight; however, in this step, we must integrate all weight vectors with respect to each decision maker. For the integration of the decision maker's opinions for each criterion based on membership functions, the following formula is employed:

$$
M F \tilde{\mathrm{C}}_{j}=\left(\frac{\sum_{k=1}^{t} e_{j k}^{l}}{t}, \frac{\sum_{k=1}^{t} e_{j k}^{m}}{t}, \frac{\sum_{k=1}^{t} e_{j k}^{r}}{t}\right) ; \quad j=1,2, \ldots, n
$$

where $e_{j k}$ denotes the membership function of the $j$ th criterion in regard of the $k$ th decision maker thought in the fuzzy judgment matrix. Also, $M F \tilde{C}_{j}$ is defined as the integration of membership function for $j$ th criterion with respect to all decision makers. To express the relative distance between each membership function of criteria with respect to all membership functions (MFC), we introduced the crisp initial weight for all criteria. The minimum and maximum MFCs have the lowest and highest weights, respectively. In fact, the crisp initial weights represent the distance of each MFC from the minimum and maximum MFCs. Hence, the initial weights of the $j$ th criterion can be calculated with the following equations:

For positive concept:

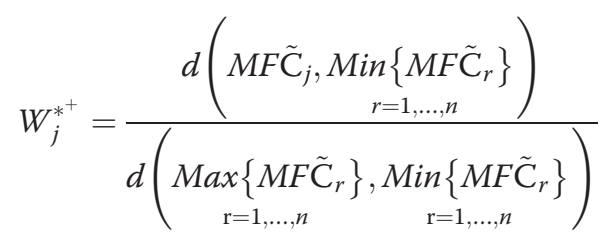

For negative concept:

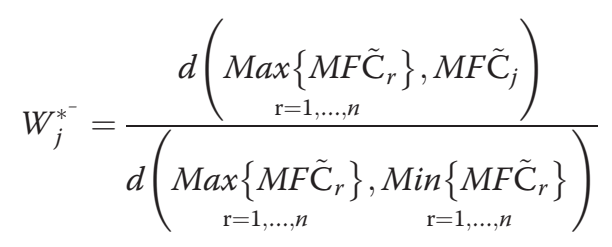

Now, the crisp value of the normalized subjective weights of the $j$ th criterion is obtained as follows:

$$
W_{j}^{S}=\frac{W_{j}^{*}}{\sum_{j=1}^{n} W_{j}^{*}} ; \quad \sum_{j=1}^{n} W_{j}^{S}=1 ; \quad j=1, \ldots, n
$$

Step 3.2. Objective weights. The objective approaches select weights through mathematical calculation, which neglects any subjective judgment information of decision makers. The objective weights for the $j$ th criterion with regard to the $k$ th decision maker are achieved using the following formulas: 


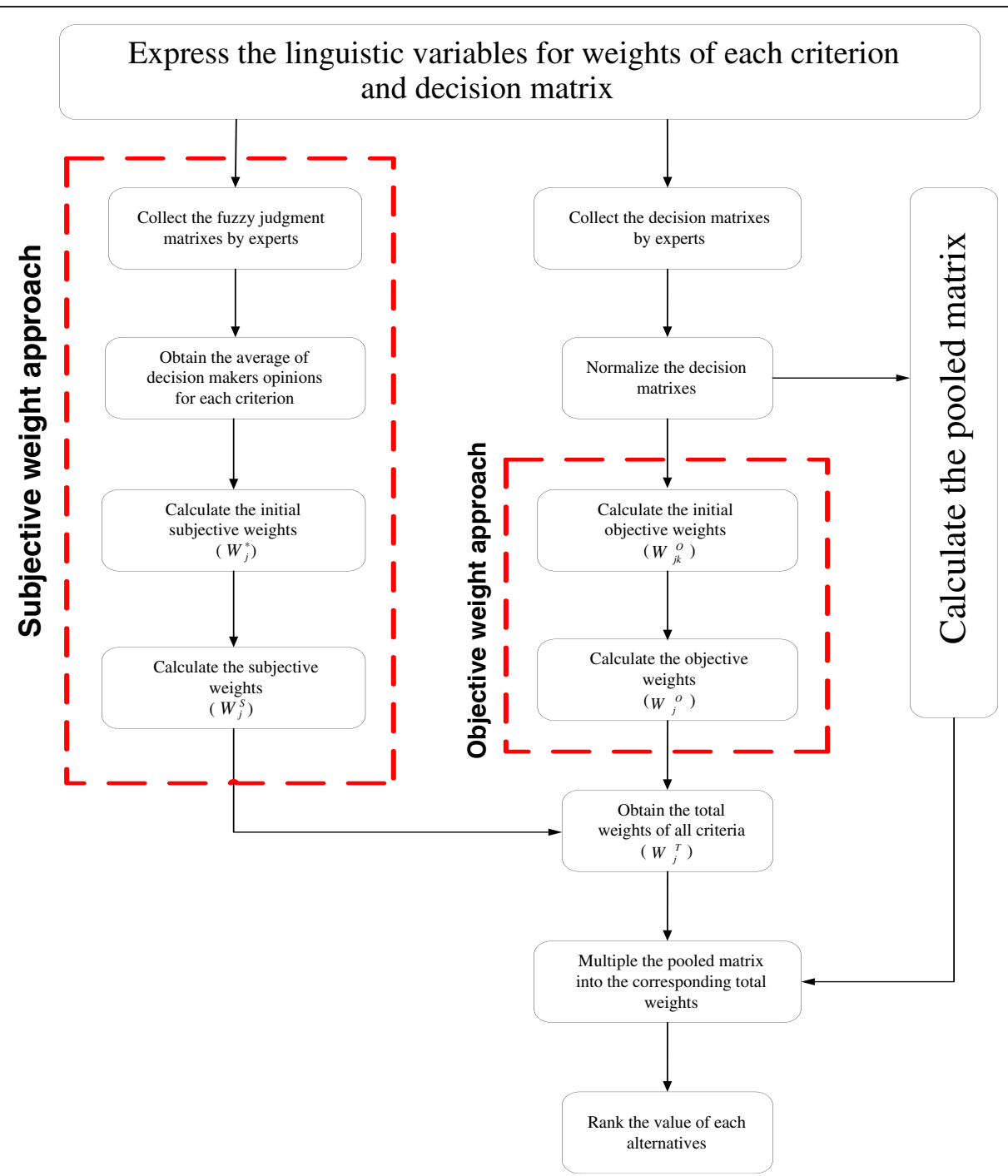

Figure 1 The structure of the proposed method.

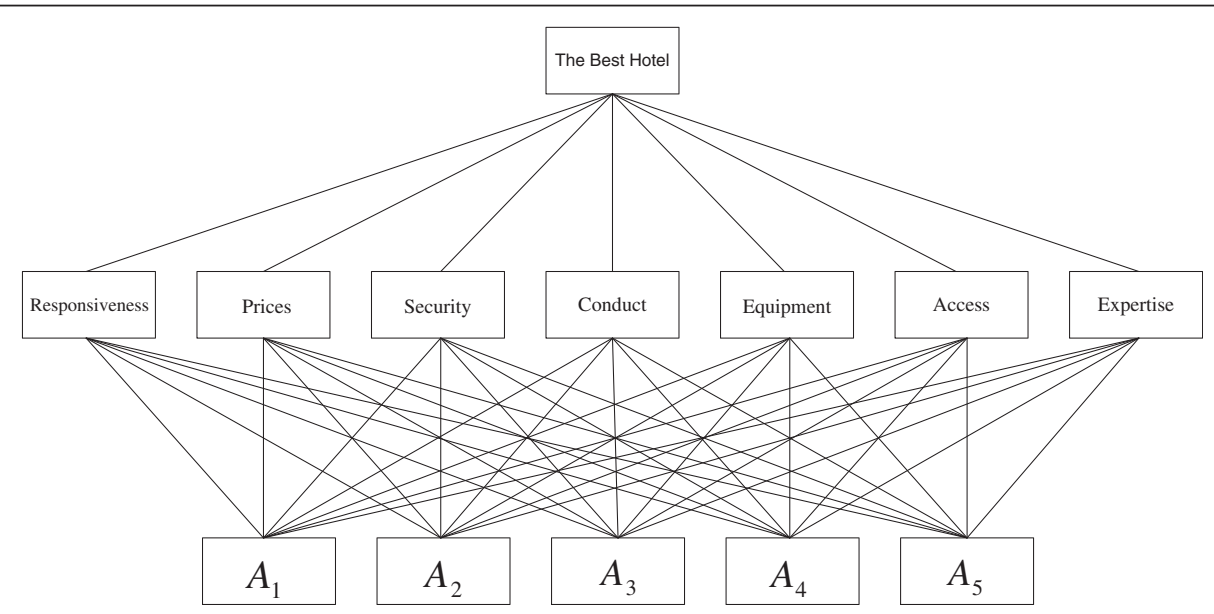

Figure 2 Decision-making hierarchical structure. 
Table 1 Fuzzy linguistic terms for each criterion

\begin{tabular}{lccc}
\hline Importance & Abbreviation & \multicolumn{2}{c}{ Fuzzy number } \\
\cline { 3 - 4 } & & All criteria except $\boldsymbol{C}_{\mathbf{2}}$ & $\boldsymbol{C}_{\mathbf{2}}$ \\
\hline Very low & $\mathrm{VL}$ & $(0,0,1)$ & $(0,0,50)$ \\
Low & $\mathrm{L}$ & $(0,1,3)$ & $(0,50,150)$ \\
Medium low & $\mathrm{ML}$ & $(1,3,5)$ & $(50,150,200)$ \\
Medium & $\mathrm{M}$ & $(3,5,7)$ & $(150,200,250)$ \\
Medium high & $\mathrm{MH}$ & $(5,7,9)$ & $(200,250,350)$ \\
High & $\mathrm{H}$ & $(7,9,10)$ & $(250,350,400)$ \\
Very high & $\mathrm{VH}$ & $(9,9,10)$ & $(350,400,400)$ \\
\hline
\end{tabular}

For positive concept:

$$
W_{j k}^{O^{+}}=\frac{\sum_{i=1}^{m} d^{2}\left(\operatorname{Max}\left(\tilde{Y}_{j}^{k}\right), \tilde{Y}_{i j}^{k}\right)}{\sum_{j=1}^{n} \sum_{i=1}^{m} d^{2}\left(\operatorname{Max}\left(\tilde{Y}_{j}^{k}\right), \tilde{Y}_{i j}^{k}\right)} ; j=1, \ldots, n ; k=1,2, \ldots, t
$$

For negative concept:

$$
W_{j k}^{O^{-}}=\frac{\sum_{i=1}^{m} d^{2}\left(\tilde{Y}_{i j}^{k}, \operatorname{Min}\left(\tilde{Y}_{j}^{k}\right)\right)}{\sum_{j=1}^{n} \sum_{i=1}^{m} d^{2}\left(\tilde{Y}_{i j}^{k}, \operatorname{Min}\left(\tilde{Y}_{j}^{k}\right)\right)} ; j=1, \ldots, n ; k=1,2, \ldots, t
$$

where $\tilde{Y}_{i j}^{k}$ represents the $i$ th alternative of the $j$ th criteria in the $k$ th decision maker in the normalized matrix. Also, $\tilde{Y}_{j}^{k}$ represents the best value (it may have a positive or negative concept) of the $j$ th criteria in view of the $k$ th decision maker in the normalized matrix. Then, the objective weights for each criterion as crisp value are obtained by the average of $W_{j k}^{O}$ according to the following equation:

$$
W_{j}^{O}=\frac{\sum_{k=1}^{t} W_{j k}^{O}}{t} ; \sum_{j=1}^{n} W_{j}^{O}=1 ; j=1, \ldots, n
$$

Step 4. Integration of both objective and subjective weights is performed in this step. Combined fuzzy weight tells us that if the values of a criterion in different alternatives do not differ much from each other, then the criterion will not be so important in the decision-making process, though this criterion may not seem very important to the decision maker. Only those criteria whose values in different alternatives differ significantly can play important roles in decision-making processes. Combined fuzzy weight is such an indicator that not only shows how important a criterion is to the decision-maker but also shows how different the values of the criteria in different alternatives are. To do this, we introduce two coefficient factors for objective and subjective weights of decision makers. Thus, $\alpha$ and $\beta$ represent the coefficients of objective and subjective weights, respectively. Total weights of all criteria, $W_{j}^{T}$, are obtained using the following formula (Ma et al. 1999):

$$
W_{j}^{T}=\alpha \times\left(W_{j}^{O}\right)+\beta \times\left(W_{j}^{S}\right) ; \alpha+\beta=1
$$
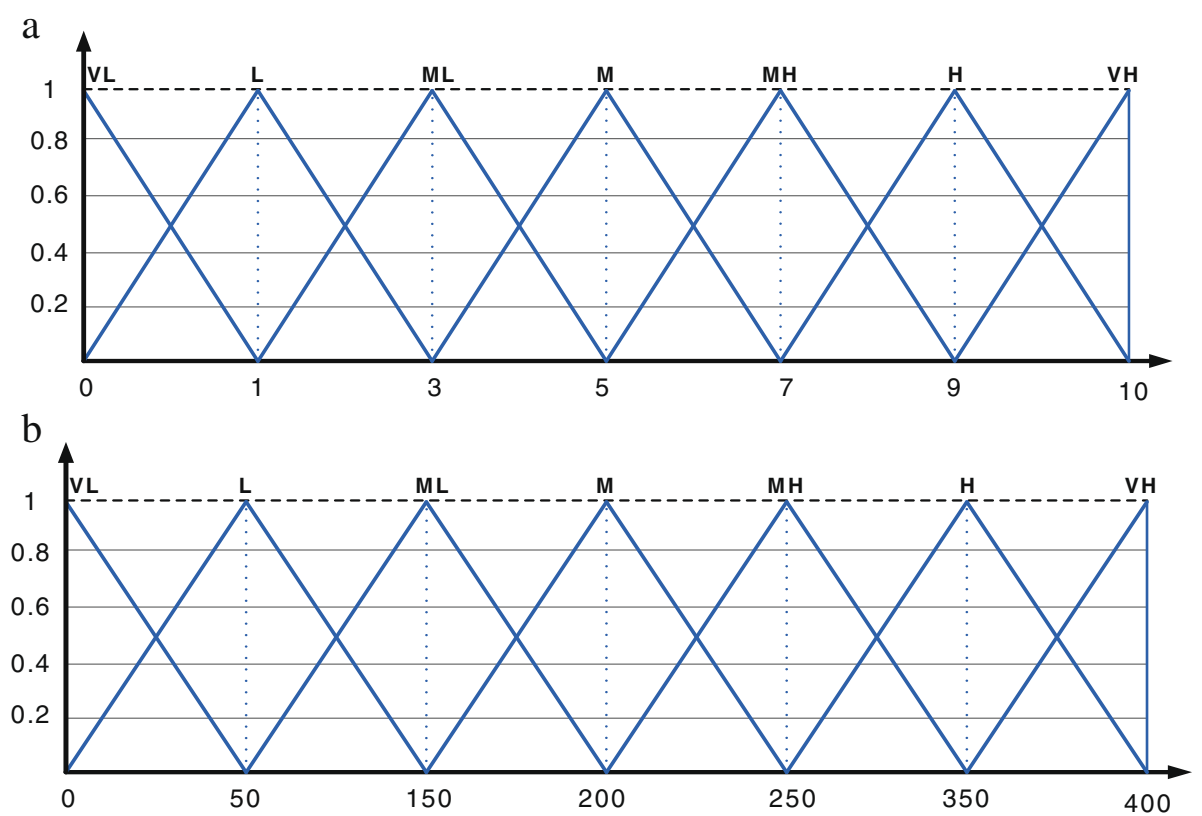

Figure 3 Fuzzy number representation by decision makers for criteria. (a) Fuzzy number for each criterion except $C_{2}$. (b) Fuzzy number for criterion $C_{2}$. 
Table 2 The initial decision maker ideas

\begin{tabular}{ccccccccc}
\hline Decision maker & Alternative & $\boldsymbol{C}_{\mathbf{1}}$ & $\boldsymbol{C}_{\mathbf{2}}$ & $\boldsymbol{C}_{\mathbf{3}}$ & $\boldsymbol{C}_{\mathbf{4}}$ & $\boldsymbol{C}_{\mathbf{5}}$ & $\boldsymbol{C}_{\mathbf{6}}$ & $\boldsymbol{C}_{\mathbf{7}}$ \\
\hline$D_{1}$ & $A_{1}$ & $(1,3,5)$ & $(200,250,350)$ & $(5,7,9)$ & $(3,5,7)$ & $(0,1,3)$ & $(5,7,9)$ & $(7,9,10)$ \\
& $A_{2}$ & $(5,7,9)$ & $(250,350,400)$ & $(5,7,9)$ & $(3,5,7)$ & $(7,9,10)$ & $(7,9,10)$ & $(7,9,10)$ \\
& $A_{3}$ & $(7,9,10)$ & $(200,250,350)$ & $(7,9,10)$ & $(1,3,5)$ & $(1,3,5)$ & $(9,9,10)$ & $(5,7,9)$ \\
& $A_{4}$ & $(3,5,7)$ & $(250,350,400)$ & $(5,7,9)$ & $(7,9,10)$ & $(1,3,5)$ & $(5,7,9)$ & $(7,9,10)$ \\
& $A_{5}$ & $(3,5,7)$ & $(350,350,400)$ & $(5,7,9)$ & $(5,7,9)$ & $(0,0,1)$ & $(9,9,10)$ & $(5,7,9)$ \\
$D_{2}$ & $A_{1}$ & $(1,3,5)$ & $(150,200,250)$ & $(7,9,10)$ & $(5,7,9)$ & $(0,0,1)$ & $(5,7,9)$ & $(7,9,10)$ \\
& $A_{2}$ & $(3,5,7)$ & $(350,400,400)$ & $(7,9,10)$ & $(1,3,5)$ & $(5,7,9)$ & $(9,9,10)$ & $(5,7,9)$ \\
& $A_{3}$ & $(5,7,9)$ & $(150,200,250)$ & $(7,9,10)$ & $(1,3,5)$ & $(0,0,1)$ & $(7,9,10)$ & $(5,7,9)$ \\
& $A_{4}$ & $(3,5,7)$ & $(50,150,200)$ & $(5,7,9)$ & $(5,7,9)$ & $(1,3,5)$ & $(5,7,9)$ & $(7,9,10)$ \\
& $A_{5}$ & $(1,3,5)$ & $(250,350,400)$ & $(5,7,9)$ & $(3,5,7)$ & $(1,3,5)$ & $(7,9,10)$ & $(7,9,10)$ \\
& $A_{1}$ & $(1,3,5)$ & $(50,150,200)$ & $(7,9,10)$ & $(3,5,7)$ & $(0,0,1)$ & $(5,7,9)$ & $(5,7,9)$ \\
& $A_{2}$ & $(5,7,9)$ & $(250,350,400)$ & $(5,7,9)$ & $(1,3,5)$ & $(5,7,9)$ & $(5,7,9)$ & $(7,9,10)$ \\
& $A_{3}$ & $(7,9,10)$ & $(250,350,400)$ & $(5,7,9)$ & $(3,5,7)$ & $(0,0,1)$ & $(7,9,10)$ & $(7,9,10)$ \\
& $A_{4}$ & $(5,7,9)$ & $(200,250,350)$ & $(5,7,9)$ & $(7,9,10)$ & $(0,0,1)$ & $(5,7,9)$ & $(5,7,9)$ \\
& $A_{5}$ & $(1,3,5)$ & $(150,200,250)$ & $(7,9,10)$ & $(5,7,9)$ & $(1,3,5)$ & $(7,9,10)$ & $(7,9,10)$ \\
& & & & & & & &
\end{tabular}

To investigate the impact of coefficients on the selection of the alternative with best environmental performance, we conducted the sensitivity analysis.

Step 5. To distinguish the best alternative, the normalized decision matrix is multiplied by the elements of total weight which were obtained in the previous step. Hence, in this step the aggregation of the normalized decision matrix is employed. This is called a pooled decision matrix $\tilde{D}^{P}$. The pooled decision matrix is calculated using the $k$ th normalized decision matrix, $\tilde{D}_{k}^{N}$, as follows:

$$
\begin{aligned}
\tilde{D}^{P}= & {\left[\tilde{Y}_{i j}^{P}=\left(\frac{\sum_{k=1}^{t} y_{i j}^{l}}{t}, \frac{\sum_{k=1}^{t} y_{i j}^{m}}{t}, \frac{\sum_{k=1}^{t} y_{i j}^{r}}{t}\right)\right]_{m n} ; } \\
& i=1, \ldots, m ; j=1, \ldots, n
\end{aligned}
$$

\begin{tabular}{|c|c|c|c|c|c|c|c|c|}
\hline Decision maker & Alternative & $C_{1}$ & $C_{2}$ & $C_{3}$ & $C_{4}$ & $C_{5}$ & $C_{6}$ & $C_{7}$ \\
\hline \multirow[t]{5}{*}{$D_{1}$} & $A_{1}$ & $(0.1,0.3,0.5)$ & $(0.57,0.8,1)$ & $(0.5,0.7,0.9)$ & $(0.3,0.5,0.7)$ & $(0,0.1,0.3)$ & $(0.5,0.7,0.9)$ & $(0.7,0.9,1)$ \\
\hline & $A_{2}$ & $(0.5,0.7,0.9)$ & $(0.5,0.57,0.8)$ & $(0.5,0.7,0.9)$ & $(0.3,0.5,0.7)$ & $(0.7,0.9,1)$ & $(0.7,0.9,1)$ & $(0.7,0.9,1)$ \\
\hline & $A_{3}$ & $(0.7,0.9,1)$ & $(0.57,0.8,1)$ & $(0.7,0.9,1)$ & $(0.1,0.3,0.5)$ & $(0.1,0.3,0.5)$ & $(0.9,0.9,1)$ & $(0.5,0.7,0.9)$ \\
\hline & $A_{4}$ & $(0.3,0.5,0.7)$ & $(0.5,0.57,0.8)$ & $(0.5,0.7,0.9)$ & $(0.7,0.9,1)$ & $(0.1,0.3,0.5)$ & $(0.5,0.7,0.9)$ & $(0.7,0.9,1)$ \\
\hline & $A_{5}$ & $(0.3,0.5,0.7)$ & $(0.5,0.57,0.57)$ & $(0.5,0.7,0.9)$ & $(0.5,0.7,0.9)$ & $(0,0,0.1)$ & $(0.9,0.9,1)$ & $(0.5,0 ., 70.9)$ \\
\hline \multirow[t]{5}{*}{$D_{2}$} & $A_{1}$ & $(0.11,0.33,0.56)$ & $(0.2,0.25,0.33)$ & $(0.7,0.9,1)$ & $(0.56,0.78,1)$ & $(0,0,0.11)$ & $(0.5,0.7,0.9)$ & $(0.7,0.9,1)$ \\
\hline & $A_{2}$ & $(0.33,0.56,0.78)$ & $(0.13,0.13,0.14)$ & $(0.7,0.9,1)$ & $(0.11,0.33,0.56)$ & $(0.56,0.78,1)$ & $(0.9,0.9,1)$ & $(0.5,0.7,0.9)$ \\
\hline & $A_{3}$ & $(0.56,0.78,1)$ & $(0.2,0.25,0.33)$ & $(0.7,0.9,1)$ & $(0.11,0.33,0.56)$ & $(0,0,0.11)$ & $(0.7,0.9,1)$ & $(0.5,0.7,0.9)$ \\
\hline & $A_{4}$ & $(0.33,0.56,0.78)$ & $(0.25,0.33,1)$ & $(0.5,0.7,0.9)$ & $(0.56,0.78,1)$ & $(0.11,0.33,0.56)$ & $(0.5,0.7,0.9)$ & $(0.7,0.9,1)$ \\
\hline & $A_{5}$ & $(0.11,0.33,0.56)$ & $(0.13,0.14,0.2)$ & $(0.5,0.7,0.9)$ & $(0.33,0.56,0.78)$ & $(0.11,0.33,0.56)$ & $(0.7,0.9,1)$ & $(0.7,0.9,1)$ \\
\hline \multirow[t]{5}{*}{$D_{3}$} & $A_{1}$ & $(0.1,0.3,0.5)$ & $(0.25,0.33,1)$ & $(0.7,0.9,1)$ & $(0.3,0.5,0.7)$ & $(0,0,0.11)$ & $(0.5,0.7,0.9)$ & $(0.5,0.7,0.9)$ \\
\hline & $A_{2}$ & $(0.5,0.7,0.9)$ & $(0.13,0.14,0.2)$ & $(0.5,0.7,0.9)$ & $(0.1,0.3,0.5)$ & $(0.56,0.78,1)$ & $(0.5,0.7,0.9)$ & $(0.7,0.9,1)$ \\
\hline & $A_{3}$ & $(0.7,0.9,1)$ & $(0.13,0.14,0.2)$ & $(0.5,0.7,0.9)$ & $(0.3,0.5,0.7)$ & $(0,0,0.11)$ & $(0.7,0.9,1)$ & $(0.7,0.9,1)$ \\
\hline & $A_{4}$ & $(0.5,0.7,0.9)$ & $(0.14,0.2,0.25)$ & $(0.5,0.7,0.9)$ & $(0.7,0.9,1)$ & $(0,0,0.11)$ & $(0.5,0.7,0.9)$ & $(0.5,0.7,0.9)$ \\
\hline & $A_{5}$ & $(0.1,0.3,0.5)$ & $(0.2,0.25,0.33)$ & $(0.7,0.9,1)$ & $(0.5,0.7,0.9)$ & $(0.11,0.33,0.56)$ & $(0.7,0.9,1)$ & $(0.7,0.9,1)$ \\
\hline
\end{tabular}

Table 3 The normalized decision maker ideas 
where $\tilde{Y}_{i j}^{P}$ denotes the value of $i$ th alternative with respect to the $j$ th criterion in the pooled decision matrix. We derive total fuzzy scores $\tilde{F}_{i}$ for individual alternatives by multiplying the fuzzy pooled decision matrix $\tilde{D}^{P}$ by their corresponding total weight vectors $W_{j}^{T}$.

$$
\begin{aligned}
\tilde{F}=\tilde{D}^{P} \otimes W^{T} & =\left[\begin{array}{cccc}
\tilde{Y}_{11}^{P} & \tilde{Y}_{12}^{P} & \ldots & \tilde{Y}_{1 n}^{P} \\
\tilde{Y}_{21}^{P} & \tilde{Y}_{22}^{P} & \ldots & \tilde{Y}_{2 n}^{P} \\
\vdots & \vdots & \vdots & \vdots \\
\tilde{Y}_{m 1}^{P} & \tilde{Y}_{m 2}^{P} & \ldots & \tilde{Y}_{m n}^{P}
\end{array}\right] \otimes\left[\begin{array}{c}
W_{1}^{T} \\
W_{2}^{T} \\
\vdots \\
W_{n}^{T}
\end{array}\right] \\
& =\left[\begin{array}{c}
\tilde{Y}_{11}^{P} \otimes W_{1}^{T} \oplus \tilde{Y}_{12}^{P} \otimes W_{2}^{T} \oplus \ldots \oplus \tilde{Y}_{1 n}^{P} \otimes W_{n}^{T} \\
\tilde{Y}_{21}^{P} \otimes W_{1}^{T} \oplus \tilde{Y}_{22}^{P} \otimes W_{2}^{T} \oplus \ldots \oplus \tilde{Y}_{2 n}^{P} \otimes W_{n}^{T} \\
\tilde{Y}_{m 1}^{P} \otimes W_{1}^{T} \oplus \tilde{Y}_{m 2}^{P} \otimes W_{2}^{T} \oplus \ldots \oplus \tilde{Y}_{m n}^{P} \otimes W_{n}^{T}
\end{array}\right] \\
& =\left[\begin{array}{c}
\tilde{f}_{1} \\
\tilde{f}_{2} \\
\vdots \\
\tilde{f}_{m}
\end{array}\right]=\left[\tilde{f}_{i}\right]_{m \times 1}
\end{aligned}
$$

Step 6. After obtaining the total fuzzy scores for each alternative $\tilde{F}=\left[\tilde{f}_{i}\right]_{m \times 1}$, we then must compute a crisp value for each total score and select the alternative(s) with the maximum total score. As indicated in the literature review, many approaches have been introduced to rank the fuzzy numbers. To do this, we rank the total fuzzy scores $\tilde{F}=\left[\tilde{f}_{i}\right]_{m \times 1}$ by the signed distance to determine the best location. In fact, in this approach, the distance of each fuzzy score with respect to the maximum and minimum distances of all fuzzy scores is calculated. Let $\tilde{f}_{i}=\left(f_{i}^{l}, f_{i}^{m}, f_{i}^{r}\right) ; i=1, \ldots, m$ be a total fuzzy number; therefore, the following equations calculate crisp total scores of individual locations:

$$
\begin{aligned}
x_{i} & =\frac{\left(f_{i}^{l}+f_{i}^{m}+f_{i}^{r}\right)}{3} \\
I_{\tilde{f}_{i}} & =\frac{d\left(\tilde{f}_{i}, \underset{s=1, \ldots, \mathrm{m}}{\operatorname{Min}}\left(\tilde{f}_{s}\right)\right)}{d\left(\underset{s=1, \ldots, \mathrm{m}}{\operatorname{Max}}\left(\tilde{f}_{s}\right), \underset{s=1, \ldots, \mathrm{m}}{\operatorname{Min}}\left(\tilde{f}_{s}\right)\right)} \times x_{i}
\end{aligned}
$$

where $I_{\tilde{f}_{i}}$ gives the crisp value of the total fuzzy score of location $A_{i}$ using the signed distance. The analytical

Table 4 Linguistic terms and membership function

\begin{tabular}{lcc}
\hline Linguistic terms & Abbreviation & Membership function \\
\hline Extremely unimportant & $\mathrm{EU}$ & $(1,1,3)$ \\
Very unimportant & $\mathrm{VU}$ & $(1,3,5)$ \\
Important & $\mathrm{I}$ & $(3,5,7)$ \\
Very important & $\mathrm{VI}$ & $(5,7,9)$ \\
Extremely important & $\mathrm{El}$ & $(7,9,9)$ \\
\hline
\end{tabular}

Table 5 Subjective weight (fuzzy judgment matrix)

\begin{tabular}{lcccc}
\hline Criteria & \multicolumn{3}{c}{ Decision makers } & MFC \\
\cline { 2 - 4 } & $\boldsymbol{D}_{\mathbf{1}}$ & $\boldsymbol{D}_{\mathbf{2}}$ & $\boldsymbol{D}_{\mathbf{3}}$ & \\
\hline$C_{1}$ & $(3,5,7)$ & $(5,7,9)$ & $(5,7,9)$ & $(4.33,6.33,8.33)$ \\
$C_{2}$ & $(5,7,9)$ & $(3,5,7)$ & $(3,5,7)$ & $(3.67,5.67,7.67)$ \\
$C_{3}$ & $(7,9,9)$ & $(5,7,9)$ & $(7,9,9)$ & $(6.33,8.33,9)$ \\
$C_{4}$ & $(3,5,7)$ & $(1,3,5)$ & $(3,5,7)$ & $(2.33,4.33,6.33)$ \\
$C_{5}$ & $(1,3,5)$ & $(1,3,5)$ & $(3,5,7)$ & $(1.67,3.67,5.67)$ \\
$C_{6}$ & $(1,1,3)$ & $(1,1,3)$ & $(1,3,5)$ & $(1,1.67,3.67)$ \\
$C_{7}$ & $(5,7,9)$ & $(5,7,9)$ & $(7,9,9)$ & $(5.67,7.67,9)$ \\
\hline
\end{tabular}

structure of the proposed method is illustrated in Figure 1. To determine the performance of the proposed method, we apply the proposed method in a case study in the next section.

\section{Numerical illustration}

Tourism attracted 2.3 million people to Iran in 2009. Iran plans to have 20 million tourists annually by 2015 (including domestic tourism). The landscape of Iran is diverse and beautiful, providing a range of activities from hiking and skiing in the Alborz Mountains to beach holidays in the Persian Gulf and the Caspian Sea. Also, domestic tourism in Iran is one of the largest in the world. Despite the international tensions, the government continues to project a strong rise in visitor numbers and tourism revenue over the forecast period and to talk of projects to build an additional 100 hotels. According to Iranian officials, in a change of trend, about 1,659,000 foreign tourists visited Iran in 2004; most came from Asian countries, including the republics of Central Asia, while a small share (about 10\%) came from North America and the European Union including Germany, Italy, Bulgaria, France, and Belgium. The most popular tourist destination is Tehran (Iran Travel and Tourism Forecast 2008). In an effort to study the quality of service of the hotels, a regular survey is usually done in five hotels in the capital of Iran (Tehran): Azadi Hotel $\left(A_{1}\right)$, Evin Hotel $\left(A_{2}\right)$, Esteghlal Hotel $\left(A_{3}\right)$, Enghelab Hotel $\left(A_{4}\right)$, and Laleh Hotel $\left(A_{5}\right)$. Due to the fact that most researchers in the literature

Table 6 Subjective and objective weights

\begin{tabular}{lccllll}
\hline Criteria & $\boldsymbol{w}^{*}$ & $\boldsymbol{w}^{\mathbf{s}}$ & $\mathbf{w}_{\mathbf{D}_{1}}^{\mathbf{O}}$ & $\mathbf{w}_{\mathbf{D}_{2}}^{O}$ & $\mathbf{w}_{\mathbf{D}_{3}}^{O}$ & $\boldsymbol{w}^{\mathbf{O}}$ \\
\hline$C_{1}$ & 0.72 & 0.20 & 0.190 & 0.199 & 0.198 & 0.196 \\
$C_{2}$ & 0.39 & 0.11 & 0.075 & 0.094 & 0.063 & 0.077 \\
$C_{3}$ & 1 & 0.27 & 0.089 & 0.052 & 0.069 & 0.070 \\
$C_{4}$ & 0.39 & 0.11 & 0.190 & 0.165 & 0.198 & 0.185 \\
$C_{5}$ & 0.28 & 0.08 & 0.348 & 0.356 & 0.356 & 0.353 \\
$C_{6}$ & 0 & 0 & 0.063 & 0.082 & 0.069 & 0.072 \\
$C_{7}$ & 0.92 & 0.25 & 0.044 & 0.052 & 0.046 & 0.048 \\
\hline
\end{tabular}


Table 7 The result of sensitivity analysis on total weight

\begin{tabular}{lccccccccc}
\hline $\boldsymbol{a}$ & $\mathbf{0 . 1}$ & $\mathbf{0 . 2}$ & $\mathbf{0 . 3}$ & $\mathbf{0 . 4}$ & $\mathbf{0 . 5}$ & $\mathbf{0 . 6}$ & $\mathbf{0 . 7}$ & $\mathbf{0 . 8}$ & $\mathbf{0 . 9}$ \\
\hline$w_{1}^{T}$ & 0.19543 & 0.19545 & 0.19546 & 0.19548 & 0.1955 & 0.19551 & 0.19553 & 0.19554 & 0.19556 \\
$w_{2}^{T}$ & 0.10233 & 0.09956 & 0.09678 & 0.09401 & 0.09124 & 0.08847 & 0.08569 & 0.08292 & 0.08015 \\
$w_{3}^{T}$ & 0.25065 & 0.23058 & 0.21052 & 0.19045 & 0.17038 & 0.15032 & 0.13025 & 0.11018 & 0.09012 \\
$w_{4}^{T}$ & 0.11305 & 0.12099 & 0.12894 & 0.13688 & 0.14482 & 0.15277 & 0.16071 & 0.16866 & 0.1766 \\
$w_{5}^{T}$ & 0.1031 & 0.13091 & 0.15872 & 0.18652 & 0.21433 & 0.24213 & 0.26994 & 0.29774 & 0.32555 \\
$w_{6}^{T}$ & 0.00715 & 0.01431 & 0.02146 & 0.02861 & 0.03577 & 0.04292 & 0.05007 & 0.05723 & 0.06438 \\
$w_{7}^{T}$ & 0.22828 & 0.2082 & 0.18812 & 0.16804 & 0.14796 & 0.12788 & 0.1078 & 0.08772 & 0.06765 \\
\hline
\end{tabular}

employed three decision makers to test their method, furthermore, in this research we used three experts, $D_{1}, D_{2}$, and $D_{3}$, to form a committee to act as decision makers. The criteria for service quality were generous and different. In order to establish the decision matrix for each decision maker, they express their opinions about alternatives according to each criterion using questionnaires. Seven criteria need to be considered:

$C_{1}$. Responsiveness. It measures the store personnel's ability to handle potential problems and complaints. $C_{2}$. Prices. It includes the total cost spent by customers such as reservation, pay cost for a day, restaurant, and so on.

$C_{3}$. Security. It refers to being free from danger, risk, or doubt.

$C_{4}$. Conduct. It refers to attitudes and behavior of employees.

$C_{5}$. Equipment. It includes computers and other implements used to achieve effective service delivery. $C_{6}$. Access. It involves approachability and ease of contact. $C_{7}$. Expertise. It refers to the degree of knowledge of employees about the service.

The hierarchical structure of our problem is displayed in Figure 2.

The proposed fuzzy MCDM method is applied to solve this problem, and the computational procedure is summarized as follows:

Step 1. The questionnaires use the linguistic terms for each criterion. We use triangular fuzzy numbers to express the importance of each criterion. The linguistic terms range from 'very poor' to 'very good'. All criteria except hotel prices $\left(C_{2}\right)$ have a positive concept, so in this step, the criteria can be divided into two categories: positive and negative concepts. Therefore, two types of fuzzy numbers for either positive or negative criterion are used. Table 1 illustrates each fuzzy linguistic term and its corresponding fuzzy number for each criterion.

Also, Figure 3 represents the schematic decision makers' ideas according to fuzzy numbers. For selecting the objective weights according to linguistic terms, decision makers' ideas are collected in the decision matrix. The results of decision makers' questionnaires are demonstrated in Table 2.

Step 2. To normalize all fuzzy numbers, the decision makers' ideas are transformed into the normalized matrix. The result of normalization of fuzzy numbers is shown in Table 3.

Step 3. The introduction of linguistic weighting variables (Table 4) for decision makers to assess criteria importance and the computation of aggregated fuzzy membership function weights of individual criterion are presented in Table 5.

The initial subjective weights of decision makers are obtained in this step, too. Also, subjective judgment weights $W_{j}^{S}$ are obtained by Equation 6. To obtain the objective weights, Equations 7 and 8 are used to calculate the initial objective weights for the $j$ th criterion from the $k t h$ decision maker $W_{j k}^{O}$. Afterward, using Equation 9, the objective weights are achieved. Outcomes of step 3 are depicted in Table 6.

Table 8 Pooled decision matrix

\begin{tabular}{lccccccc}
\hline PM & $\boldsymbol{C}_{\mathbf{1}}$ & $\boldsymbol{C}_{\mathbf{2}}$ & $\boldsymbol{C}_{\mathbf{3}}$ & $\boldsymbol{C}_{\mathbf{4}}$ & $\boldsymbol{C}_{\mathbf{5}}$ & $\boldsymbol{C}_{\mathbf{6}}$ & $\boldsymbol{C}_{\mathbf{7}}$ \\
\hline$A_{1}$ & $(0.1,0.31,0.52)$ & $(0.34,0.46,0.78)$ & $(0.63,0.83,0.97)$ & $(0.39,0.59,0.8)$ & $(0,0.03,0.17)$ & $(0.5,0.7,0.9)$ & $(0.63,0.83,0.97)$ \\
$A_{2}$ & $(0.44,0.65,0.86)$ & $(0.25,0.28,0.38)$ & $(0.57,0.77,0.93)$ & $(0.17,0.38,0.59)$ & $(0.6,0.82,1)$ & $(0.7,0.83,0.97)$ & $(0.63,0.83,0.97)$ \\
$A_{3}$ & $(0.65,0.86,1)$ & $(0.3,0.4,0.51)$ & $(0.63,0.83,0.97)$ & $(0.17,0.38,0.59)$ & $(0.03,0.1,0.24)$ & $(0.77,0.9,1)$ & $(0.57,0.77,0.93)$ \\
$A_{4}$ & $(0.38,0.59,0.79)$ & $(0.3,0.37,0.68)$ & $(0.5,0.7,0.9)$ & $(0.65,0.86,1)$ & $(0.07,0.21,0.39)$ & $(0.5,0.7,0.9)$ & $(0.63,0.83,0.97)$ \\
$A_{5}$ & $(0.17,0.38,0.59)$ & $(0.28,0.32,0.37)$ & $(0.57,0.77,0.93)$ & $(0.44,0.65,0.86)$ & $(0.07,0.22,0.4)$ & $(0.77,0.9,1)$ & $(0.63,0.83,0.97)$ \\
\hline
\end{tabular}


Step 4. After obtaining the subjective and objective weights, we need to combine these weights to correspond to previous concepts that are mentioned and determine the total weights of all criteria. Therefore, two coefficients, $\alpha$ and $\beta$, are considered to analyze the significant effect on the total weights. Hence, we perform sensitivity analysis to these two coefficients. The first coefficient $\alpha$ is dedicated on how sensitive each objective weight is in affecting the ranking of total alternatives, while the second coefficient $\beta$ focuses on the subjective weights that influences the choice of the best alternative. In order to demonstrate the effect of coefficient $\alpha$ on the total weights, nine ranges of $\alpha$ are used for sensitivity analysis. Table 7 gives the total weights of each criterion based on different ranges of $\alpha$.

Step 5. To calculate the total fuzzy score $\tilde{F}_{i}$ for each alternative, we must transform the normalized decision matrix into the pooled matrix and then multiplying it with the corresponding total weight of criterion. Table 8 illustrates the pooled matrix.

Step 6. After obtaining the total fuzzy scores for each alternative, the ranking of alternative is performed. As mentioned before, the rank of each alternative depends on two coefficients of $W_{j}^{T}$. Accordingly, we use a different range of $\alpha$ to identify which of the subjective and objective weights of criteria is most influential in selecting the alternatives. The result of this step is demonstrated in Table 9.

Note that several ranges of $\alpha$ are generated from the uniform distribution of the interval $[0,1]$. The results show that when the coefficient $\alpha$ grows with the fixed slope, the alternative ranking orders is placed in a stable situation. It means that the subjective weights have no influence on the ranking when $\alpha$ is increased. On the other hand, if coefficient $\alpha$ decreases with the fixed slope, the trend of results becomes disordered. However, with the increasing subjective weight of decision maker's judgment for each criterion, our decision is more arbitrary. This consequence shows that the Azadi Hotel according to our proposed method has the least rank for different amounts of $\alpha$. When the $\alpha$ range decreases, then Evin Hotel is placed at the first rank followed by Enghelab Hotel and Esteghlal Hotel, respectively. Results show that for all ranges of $\alpha$, Evin Hotel is ranked in first place. Many ranking methods for fuzzy numbers have been proposed so far. A list of these methods has been presented by Chen and Hwang (1992). In this sense, for the performance evolution of the proposed method to rank the fuzzy numbers, we compare our method with three common approaches in the fuzzy environment.

\section{Cheng method}

Cheng (1998) improved the concept of ranking fuzzy numbers using fuzzy mean and fuzzy standard deviation as proposed by Lee and Li (1988). According to Lee and
Table 9 The result of sensitivity analysis

\begin{tabular}{|c|c|c|c|c|}
\hline$a$ & Alternative & Total fuzzy score $\left(f_{i}\right)$ & $I_{f i}$ & Rank $\left(A_{i}\right)$ \\
\hline \multirow[t]{5}{*}{0.1} & $A_{1}$ & $(0.41,0.58,0.76)$ & 0.275 & 4 \\
\hline & $A_{2}$ & $(0.47,0.65,0.82)$ & 0.649 & 1 \\
\hline & $A_{3}$ & $(0.45,0.62,0.76)$ & 0.442 & 2 \\
\hline & $A_{4}$ & $(0.42,0.59,0.77)$ & 0.335 & 3 \\
\hline & $A_{5}$ & $(0.36,0.53,0.67)$ & 0 & 5 \\
\hline \multirow[t]{5}{*}{0.2} & $A_{1}$ & $(0.39,0.56,0.74)$ & 0 & 5 \\
\hline & $A_{2}$ & $(0.48,0.67,0.84)$ & 0.664 & 1 \\
\hline & $A_{3}$ & $(0.46,0.63,0.82)$ & 0.383 & 3 \\
\hline & $A_{4}$ & $(0.45,0.63,0.82)$ & 0.415 & 2 \\
\hline & $A_{5}$ & $(0.4,0.58,0.74)$ & 0.070 & 4 \\
\hline \multirow[t]{5}{*}{0.3} & $A_{2}$ & $(0.37,0.53,0.71)$ & 0 & 5 \\
\hline & $A_{3}$ & $(0.48,0.67,0.84)$ & 0.663 & 1 \\
\hline & $A_{4}$ & $(0.44,0.61,0.76)$ & 0.321 & 3 \\
\hline & $A_{5}$ & $(0.43,0.61,0.8)$ & 0.380 & 2 \\
\hline & $A_{1}$ & $(0.38,0.56,0.72)$ & 0.093 & 4 \\
\hline \multirow[t]{5}{*}{0.4} & $A_{2}$ & $(0.35,0.51,0.69)$ & 0 & 5 \\
\hline & $A_{3}$ & $(0.48,0.67,0.84)$ & 0.662 & 1 \\
\hline & $A_{4}$ & $(0.42,0.59,0.74)$ & 0.276 & 3 \\
\hline & $A_{5}$ & $(0.42,0.6,0.79)$ & 0.353 & 2 \\
\hline & $A_{2}$ & $(0.37,0.55,0.71)$ & 0.107 & 4 \\
\hline \multirow[t]{5}{*}{0.5} & $A_{2}$ & $(0.33,0.49,0.67)$ & 0 & 5 \\
\hline & $A_{3}$ & $(0.48,0.67,0.84)$ & 0.661 & 1 \\
\hline & $A_{4}$ & $(0.41,0.57,0.72)$ & 0.242 & 3 \\
\hline & $A_{5}$ & $(0.41,0.59,0.77)$ & 0.332 & 2 \\
\hline & $A_{1}$ & $(0.36,0.53,0.7)$ & 0.116 & 4 \\
\hline \multirow[t]{5}{*}{0.6} & $A_{2}$ & $(0.31,0.46,0.64)$ & 0 & 5 \\
\hline & $A_{3}$ & $(0.48,0.67,0.84)$ & 0.661 & 1 \\
\hline & $A_{4}$ & $(0.39,0.55,0.7)$ & 0.215 & 3 \\
\hline & $A_{5}$ & $(0.39,0.57,0.76)$ & 0.315 & 2 \\
\hline & $A_{2}$ & $(0.34,0.52,0.68)$ & 0.122 & 4 \\
\hline \multirow[t]{5}{*}{0.7} & $A_{2}$ & $(0.29,0.44,0.62)$ & 0 & 5 \\
\hline & $A_{3}$ & $(0.48,0.66,0.84)$ & 0.660 & 1 \\
\hline & $A_{4}$ & $(0.37,0.53,0.67)$ & 0.193 & 3 \\
\hline & $A_{5}$ & $(0.38,0.56,0.75)$ & 0.299 & 2 \\
\hline & $A_{1}$ & $(0.33,0.5,0.67)$ & 0.126 & 4 \\
\hline \multirow[t]{5}{*}{0.8} & $A_{2}$ & $(0.27,0.41,0.6)$ & 0 & 5 \\
\hline & $A_{3}$ & $(0.47,0.66,0.84)$ & 0.659 & 1 \\
\hline & $A_{4}$ & $(0.35,0.51,0.65)$ & 0.174 & 3 \\
\hline & $A_{5}$ & $(0.37,0.54,0.73)$ & 0.286 & 2 \\
\hline & $A_{2}$ & $(0.32,0.49,0.65)$ & 0.128 & 4 \\
\hline \multirow[t]{5}{*}{0.9} & $A_{2}$ & $(0.25,0.39,0.57)$ & 0 & 5 \\
\hline & $A_{3}$ & $(0.47,0.66,0.84)$ & 0.658 & 1 \\
\hline & $A_{4}$ & $(0.34,0.48,0.63)$ & 0.158 & 3 \\
\hline & $A_{5}$ & $(0.36,0.53,0.72)$ & 0.274 & 2 \\
\hline & $A_{1}$ & $(0.3,0.47,0.64)$ & 0.129 & 4 \\
\hline
\end{tabular}


Li's method, the higher the mean value and, at the same time, the lower the standard deviation, then the higher is the rank of the fuzzy value. This creates a problem on how to rank fuzzy numbers: if both the mean value and standard deviation are high at the same time or the mean value and standard deviation are low at the same time. As a result, to improve Lee and Li's method, Cheng (1998) proposed a coefficient of variation (CV) index which is defined as $\frac{\sigma}{|\bar{x}|}$, in which $\sigma$ and $\bar{x}$ are the standard deviation and the mean value, respectively. In this regard, assume that the fuzzy numbers are defined as $\tilde{f}=\left(f_{1}, f_{2}, f_{3}\right)$; in which indices of the Cheng method are obtained by the following equations:

$$
\begin{aligned}
& \bar{x}=\frac{f_{1}+f_{2}+f_{3}}{3} \\
& \sigma=\frac{f_{1}^{2}+f_{2}^{2}+f_{3}^{2}-f_{1} f_{2}-f_{2} f_{3}-f_{1} f_{3}}{18}
\end{aligned}
$$

\section{Chang and Lee method}

Chang and Lee (1994) simplified the overall existence ranking index (OERI) for the use of convex fuzzy numbers. The following formula corresponds to their ranking index:

$$
\operatorname{OERI}(f)=\int_{0}^{1} w(\alpha) \times\left[\Pi_{1}(\alpha) \times \mu_{f L}^{-1}(\alpha)+\Pi_{2}(\alpha) \times \mu_{f R}^{-1}(\alpha)\right] d \alpha
$$

where $\Pi_{1}$ and $\Pi_{2}$ are subjective types of weighting, indicating neutral, optimistic, and pessimistic preferences of the decision maker, with restriction such that $\Pi_{1}+\Pi_{2}=1$. Parameter $w(\alpha)$ is used to specify weights which are to be given certain degrees of membership. Lastly, $\mu_{f L}^{-1}$ represents an inverse of the left part and $\mu_{f R}^{-1}$ is the inverse of the right part of the membership function. The limits of integration (and the limits of $\alpha$ ) are $[0,1]$.

\section{Kauffman and Gupta method}

Kaufmann and Gupta (1991) introduced a ranking method based on the removal area concept. They considered the fuzzy number $\tilde{f}=\left(f_{1}, f_{2}, f_{3}\right) ; \tilde{f} \in R^{+}$. The left removal of $\tilde{f}$, denoted by $f_{L}$, and the right removal of $\tilde{f}$, denoted by $f_{R}$, are defined as follows:

$$
\begin{aligned}
& f_{L}=f_{2}-\int_{f_{1}}^{f_{2}} F_{f}^{L}(x) d x \\
& f_{R}=f_{2}+\int_{f_{2}}^{f_{3}} F_{f}^{R}(x) d x
\end{aligned}
$$

The left and right removals stretch from the vertical axis at 0 on the $x$-axis to the left and right membership functions of $\tilde{f}$, respectively. Clearly, the fuzzy number $\tilde{f}$ becomes larger if $f_{L}$ and/or $f_{R}$, are larger. Thus, when ranking fuzzy numbers, both $f_{L}$ and $f_{R}$ must be considered. The mean of the $f_{L}$ and $f_{R}$ is then defined as follows:

$$
M(\tilde{f})=\frac{1}{2}\left(f_{L}+f_{R}\right)
$$

where $M(\tilde{f})$ is used to compare fuzzy numbers. The larger the $M(\tilde{f})$, the larger is the fuzzy number $\tilde{f}$. Now, for both fuzzy numbers $\tilde{f}_{i}$ and $\tilde{f}_{j}$

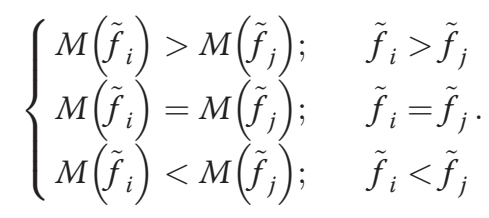

Table 10 shows that the results obtained using the proposed method are similar to those obtained using other methods.

\section{Table 10 The result of comparison}

\begin{tabular}{lllll}
\hline $\boldsymbol{a}$ & \multicolumn{5}{c}{ Rank } \\
\cline { 2 - 5 } & Proposed method & Cheng (CV) & Chang and Lee & Kauffman and Gupta \\
\hline 0.1 & $A_{2}>A_{3}>A_{4}>A_{1}>A_{5}$ & $A_{3}>A_{2}>A_{5}>A_{1}>A_{4}$ & $A_{2}>A_{3}>A_{4}>A_{5}>A_{1}$ & $A_{2}>A_{3}>A_{4}>A_{5}>A_{1}$ \\
0.2 & $A_{2}>A_{4}>A_{3}>A_{5}>A_{1}$ & $A_{3}>A_{2}>A_{5}>A_{4}>A_{1}$ & $A_{2}>A_{4}>A_{3}>A_{5}>A_{1}$ & $A_{2}>A_{4}>A_{3}>A_{5}>A_{1}$ \\
0.3 & $A_{2}>A_{4}>A_{3}>A_{5}>A_{1}$ & $A_{3}>A_{2}>A_{5}>A_{4}>A_{1}$ & $A_{2}>A_{4}>A_{3}>A_{5}>A_{1}$ & $A_{2}>A_{4}>A_{3}>A_{5}>A_{1}$ \\
0.4 & $A_{2}>A_{4}>A_{3}>A_{5}>A_{1}$ & $A_{3}>A_{2}>A_{5}>A_{4}>A_{1}$ & $A_{2}>A_{4}>A_{3}>A_{5}>A_{1}$ & $A_{2}>A_{4}>A_{3}>A_{5}>A_{1}$ \\
0.5 & $A_{2}>A_{4}>A_{3}>A_{5}>A_{1}$ & $A_{3}>A_{2}>A_{5}>A_{4}>A_{1}$ & $A_{2}>A_{4}>A_{3}>A_{5}>A_{1}$ & $A_{2}>A_{4}>A_{3}>A_{5}>A_{1}$ \\
0.6 & $A_{2}>A_{4}>A_{3}>A_{5}>A_{1}$ & $A_{3}>A_{2}>A_{5}>A_{4}>A_{1}$ & $A_{2}>A_{4}>A_{3}>A_{5}>A_{1}$ & $A_{2}>A_{4}>A_{3}>A_{5}>A_{1}$ \\
0.7 & $A_{2}>A_{4}>A_{3}>A_{5}>A_{1}$ & $A_{3}>A_{2}>A_{5}>A_{4}>A_{1}$ & $A_{2}>A_{4}>A_{3}>A_{5}>A_{1}$ & $A_{2}>A_{4}>A_{3}>A_{5}>A_{1}$ \\
0.8 & $A_{2}>A_{4}>A_{3}>A_{5}>A_{1}$ & $A_{3}>A_{2}>A_{5}>A_{4}>A_{1}$ & $A_{2}>A_{4}>A_{3}>A_{5}>A_{1}$ & $A_{2}>A_{4}>A_{3}>A_{5}>A_{1}$ \\
0.9 & $A_{2}>A_{4}>A_{3}>A_{5}>A_{1}$ & $A_{3}>A_{2}>A_{5}>A_{4}>A_{1}$ & $A_{2}>A_{4}>A_{3}>A_{5}>A_{1}$ & $A_{2}>A_{4}>A_{3}>A_{5}>A_{1}$ \\
\hline & & & &
\end{tabular}


Based on the results, the method of Cheng (CV) has not coordinated clearly among the rankings of alternatives in comparison with other ranking approaches. In addition, the proposed method can coordinate successfully and clearly among the rankings of alternative methods. After our investigations, the main point that got our attention was that Evin Hotel $\left(A_{2}\right)$ achieved the best rank of quality service using our proposed method and all of the discussed method except for Cheng's approach. It can be inferred that our method is very fast in reaching to the solution, with results highly close to those of well-known methods which can confirm the reliability of the method.

\section{Conclusions}

In this paper, an attempt was made to employ the FMCDM model to assess the service quality of tourist hotels. We investigated empirical measurements of service quality in five hotels located in Iran. Tourists' evaluation of service quality in these hotels consists of seven criteria. We used fuzzy numbers to deal with the ambiguity of concepts that are associated with the decision makers' subjective judgment and to construct subjective weights. The objective weights concurrently were determined by solving mathematical models and were amalgamated with subjective weights in the FMCDM model. The proposed approach was extended to support the situation where the preference information is given by multiple decision makers. The results of comparing the proposed method with other common methods indicated that FMCDM is more desirable than others.

\section{Appendix}

A fuzzy set $\tilde{N}$ in a universe of discourse $X$ is characterized by a membership function $\mu \tilde{N}(X)$ which associates with each element $x$ in $X$, a real number in the interval $[0,1]$. The function value $\mu \tilde{N}(X)$ is termed the grade of membership of $x$ in Bellman and Zadeh (1970).

We use triangular fuzzy numbers (shown in Figure 4). A triangular fuzzy number $\tilde{N}$ can be defined by a triplet $\left(a_{1}, a_{2}, a_{3}\right)$. Its conceptual schema and mathematical form are shown as follows:

$$
\mu_{\tilde{N}}(x)= \begin{cases}0 & x \leq a_{1} ; \\ \frac{x-a_{1}}{a_{2}-a_{1}} & a_{1}<x \leq a_{2} ; \\ \frac{a_{3}-x}{a_{3}-a_{2}} & a_{2}<x \leq a_{3} ; \\ 0 & x>a_{3} ;\end{cases}
$$

where $\left(a_{1}, a_{2}, a_{3}\right)$ denote the left-hand number, the middle number, and the right-hand number of $\tilde{N}$, respectively.

Definition 1. Assuming that both $\tilde{N}=\left(a_{1}, a_{2}, a_{3}\right)$ and $\tilde{M}=\left(b_{1}, b_{2}, b_{3}\right)$ are fuzzy numbers and $c$ is a positive real number, then the basic operations such as multiplication,

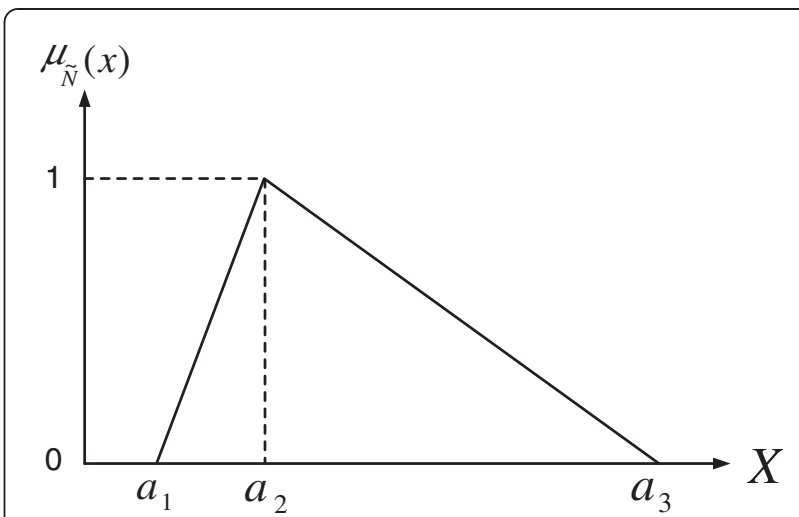

Figure 4 A triangular fuzzy number $\tilde{N}$.

addition, distance, maximum, and minimum on fuzzy triangular numbers are defined as follows, respectively (Zadeh 1965):

$$
\begin{aligned}
& c \otimes \tilde{N}=\left(c \times a_{1}, c \times a_{2}, c \times a_{3}\right) \\
& \tilde{N} \oplus \tilde{M}=\left(a_{1}+b_{1}, a_{2}+b_{2}, a_{3}+b_{3}\right) \\
& d(\tilde{N}, \tilde{M})=\left(\frac{a_{1}+2 \times a_{2}+a_{3}}{4}\right)-\left(\frac{b_{1}+2 \times b_{2}+b_{3}}{4}\right) \\
& \operatorname{Max}(\tilde{N})=\left(\operatorname{Max}\left(a_{1}\right), \operatorname{Max}\left(a_{2}\right), \operatorname{Max}\left(a_{3}\right)\right) \\
& \operatorname{Max}(\tilde{M})=\left(\operatorname{Max}\left(b_{1}\right), \operatorname{Max}\left(b_{2}\right), \operatorname{Max}\left(b_{3}\right)\right) \\
& \operatorname{Min}(\tilde{N})=\left(\operatorname{Min}\left(a_{1}\right), \operatorname{Min}\left(a_{2}\right), \operatorname{Min}\left(a_{3}\right)\right) \\
& \operatorname{Min}(\tilde{M})=\left(\operatorname{Min}\left(b_{1}\right), \operatorname{Min}\left(b_{2}\right), \operatorname{Min}\left(b_{3}\right)\right)
\end{aligned}
$$

Definition 2. When we consider a variable, in general, it takes numbers as its value. If the variable takes linguistic terms, it is called linguistic variable (Zadeh 1975; Buckley 1985). The concept of a linguistic variable is very useful to describe situations that are complex or not well defined in conventional quantitative expressions. For example, 'temperature' is a linguistic variable which contains the values as freeze, cold, cool, hot, very hot, etc., where it is defined as linguistic terms.

\section{Competing interests}

The authors declare that they have no competing interest.

\section{Authors' contributions}

Zoraghi et al. introduced a fuzzy MCDM model with object and subject approach for the evaluation in service quality process. It helps the decision makers to understand the specific information regarding the criteria used for service quality process in hotel industries. Our model can be used for various methodologies by more organizations. All authors read and approved the final manuscript.

\section{Author details}

${ }^{1}$ Faculty of Industrial and Mechanical Engineering, Islamic Azad University, P.O. Box 34185-1416, Qazvin Branch, Qazvin, Iran. ${ }^{2}$ Department of Industrial Management, Allame Tabatabaee University, Tehran, Iran. ${ }^{3}$ Department of Industrial Engineering, Payame Noor University, Tehran, Iran. ${ }^{4}$ Department of Industrial Engineering, Khatam University, Tehran, Iran.

Received: 29 August 2012 Accepted: 13 November 2013 Published: 19 Dec 2013 


\section{References}

Akama JS, Kieti DM (2003) Measuring tourist satisfaction with Kenya's wildlife safari: a case study of Tsavo West National Park. TouMang 24:73-81

Asubonteng P, McCleary KJ, Swain JE (1996) SERVQUAL revisited: a critical review of service quality. The J of Ser Mark 10:62-81

Augustyn MM, Seakhoa-King A (2004) Is the SERVQUAL scale an adequate measure of quality in leisure, tourism and hospitality. Adv in Hos and Leis 1:3-24

Awasthi A, Chauhan SS, Goyal SK (2010) A fuzzy multi criteria approach for evaluating environmental performance of suppliers. Int j of Pro Eco 126:370-378

Bellman RG, Zadeh LA (1970) Decision making a fuzzy environment. Mang Sci 17:141-164

Benítez JM, Martín JC, Román C (2007) Using fuzzy number for measuring quality of service in the hotel industry. Tou Mang 28(2):544-555

Bienstock CC, Mentzer JT, Bird MM (1997) Measuring physical distribution service quality. J of the Aca of Mark Sci 25(1):31-44

Briggs S, Sutherland J, Drummond S (2007) Are hotels serving quality? An exploratory study of service quality in the Scottish hotel sector. Tou Mang 28(4):1006-1019

Buckley JJ (1985) Fuzzy hierarchical analysis. Fuz Sets and Sys 17:233-247

Callan RJ (1999) Augmenting the range of hotel selection attributes. Int J of Tou Res 1(3):205-230

Chang PT, Lee ES (1994) Ranking of fuzzy sets based on the concept of existence. Comp and Math with App 27(9):1-21

Chen SJ, Hwang CL (1992) Fuzzy multiple attribute decision making. Springer-Verlag, Heidelberg

Chen MF, Tzeng GH, Ding CG (2003) Fuzzy MCDM approach to select service provider. IEEE Int Conf on Fuz Sys 1:572-577

Cheng CH (1998) A new approach for ranking fuzzy numbers by distance method. Fuz Sets and Sys 95:307-317

Deng H, Yeh CH, Willis RJ (2000) Inter-company comparison using modified TOPSIS with objective weights. Comp and Oper Res 27:963-973

Dube L, Renaghan LM (1999) How hotel attributes deliver the promised benefits-guests' perspectives on the lodging industry's functional best practices (part II). Cor Hotel Rest Admi Quar 40(5):89-95

Feng CM, Wang RT (2000) Performance evaluation for airlines including the consideration of financial ratios. J of Air Trans Mang 6:133-142

Gronroos C (2001) Service management and marketing: a customer relationship management approach, 2nd edition. Wiley, New York

Harrington D, Akehurst G (2000) An empirical study of service quality implementation. The SerIndu J 20(2):133-156

Hsu HM, Chen CT (1996) Aggregation of fuzzy opinions under group decision making. Fuz Sets and Sys 79:279-285

Hwang CL, Yoon KS (1981) Multiple attribute decision making: methods and applications. Springer-Verlag, Berlin

Iran Travel and Tourism Forecast (2008) Economist intelligence unit. http://en.wikipedia.org/wiki/Tourism_in_Iran. Accessed 18 August 2008

Kaufmann A, Gupta MM (1991) Introduction to fuzzy arithmetic: theory and application. Van Nostrand Reinhold, New York

Keeney R, Raiffa H (1993) Decisions with multiple objectives preferences and value tradeoffs. Cambridge University Press, New York

Lee ES, Li RJ (1988) Comparison of fuzzy numbers based on the probability measure of fuzzy events. Comp and Math with App 15(10):887-896

Liu H, Kong F (2005) A new MADM algorithm based on fuzzy subjective and objective integrated weights. Int J Inform Sys Sci 1(3-4):420-427

Ma J, Fan ZP, Huang LH (1999) A subjective and objective integrated approach to determine attribute weights. Eur J of Oper Res 112:397-404

Parasuraman A, Zeithaml VA, Berry LL (1985) A conceptual model of service quality and its implications for future research. J of Mark 49(4):41-50

Phillips PA, Sipahioglu MA (2004) Performance implications of capital structure: evidence from quoted UK organizations with hotel interests. Ser Indus J 24(5):31-51

Rozman C, Potočnik M, Pažek K, Borec A, Majkovič D, Bohanec M (2009) A multi-criteria assessment of tourist farm service quality. Tou Mang 30(5):629-637

Shyur HJ, Shih HS (2006) A hybrid MCDM model for strategic vendor selection. Math and Comp Mod 44:749-761

Sun S, Lu WM (2005) Evaluating the performance of the Taiwan hotel industry using a weight slacks-based measure. Asia Pac J of Oper Res 22(4):487-512

Ting KH (2003) A study of factors that influence the hotel service quality. Master's dissertation, Chaoyang University of Technology
Wang YJ, Lee HS, Lin K (2003) Fuzzy TOPSIS for multi-criteria decision making. Int Math J 3:367-379

Wang YJ, Lee HS (2007) Generalizing TOPSIS for fuzzy multiple-criteria group decision-making. Comp and Math with App 53:1762-1772

Yeh CH, Willis RJ, Deng H, Pan H (1999) Task oriented weighting in multi-criteria analysis. Eur J of Oper Res 119(1):130-146

Zadeh LA (1965) Fuzzy sets. Inform and Con 8:338-353

Zadeh LA (1975) The concept of a linguistic variable and its application to approximate reasoning. Inform Sci 8:199-249

Zimmermann HJ (1991) Fuzzy set theory - and its application, 2nd edition. Kluwer, Boston

10.1186/2251-712X-9-38

Cite this article as: Zoraghi et al:: A fuzzy MCDM model with objective and subjective weights for evaluating service quality in hotel industries. Journal of Industrial Engineering International 2013, 9:38

\section{Submit your manuscript to a SpringerOpen ${ }^{\odot}$ journal and benefit from:}

- Convenient online submission

- Rigorous peer review

- Immediate publication on acceptance

- Open access: articles freely available online

High visibility within the field

- Retaining the copyright to your article

Submit your next manuscript at $\gg$ springeropen.com 